\title{
Platinum-Nanoparticles on Different Types of Carbon Supports: Correlation of Electrocatalytic Activity with Carrier Morphology
}

\author{
Manfred T. Reetz ${ }^{\star}$, Hendrik Schulenburg, Marco Lopez, Bernd Spliethoff, and Bernd Tesche
}

\begin{abstract}
The electrocatalytic activity of Pt-nanoparticles used in fuel cells increases by $34 \%$ upon going from the
\end{abstract} usual Pt/Vulcan XC72 to support systems such as Pt/Printex XE2 which have a relatively rough surface strucure.

Keywords: Electrocatalysis · Fuel cells · Nanoparticles · Platinum · Transmission electron microscopy

Carbon-supported platinum nanoparticles $(\mathrm{Pt} / \mathrm{C})$ as well as various platinum alloys on carbon constitute commonly used electrocatalysts in polymer electrolyte fuel cells (PEM) [1]. They catalyze the anodic oxidation of hydrogen and the cathodic reduction of oxygen. Many preparations have been described, some involving Pt-colloids in the zero-valent form which are immobilized on high-surface conducting carbon. Irrespective of the synthetic method, Vulcan XC72 is generally employed as the carbon black [1][2]. We recently reported the preparation and carrier fixation of transition metal $o x$ ides such as $\mathrm{PtO}_{\mathrm{x}}, \mathrm{PtRuO}_{\mathrm{x}}$, and $\mathrm{PtRuOsIrO} \mathrm{x}_{\mathrm{x}}$ colloids [3]. These nanoparticles are accessible by hydrolysis of the metal salts (e.g. $\mathrm{H}_{2} \mathrm{PtCl}_{6}$ ) under basic conditions in the presence of water-soluble stabilizers. Reduction of the metal oxide colloids with formation of the metal analogs $\left(\right.$ e.g. $\left.\mathrm{PtO}_{\mathrm{x}} \rightarrow \mathrm{Pt}\right)$ can be performed either prior to immobilization or

\footnotetext{
${ }^{*}$ Correspondence: Prof. Dr. M.T. Reetz Max-Planck-Institut für Kohlenforschung Kaiser-Wilhelm-Platz 1

D-45470 Mülheim/Ruhr, Germany

Tel.: +492083062000

Fax: +4920306 2985

E-Mail: reetz@mpi-muelheim.mpg.de
}

thereafter. In view of the well-known fact that the nature of a solid support can have a profound influence on the performance of a heterogeneous catalyst [4], it is surprising that no systematic study has been carried out concerning the possible effects of utilizing different carbon blacks in electrocatalytic systems [5]. Here we demonstrate that the choice of the type of carbon black on the electrocatalytic profile of Ptnanoparticles is in fact crucial.

Carbon blacks are used in very different types of applications, e.g. as supports in electrocatalytic [1][2] and chemical [2] catalytic systems, additives in rubber tires, and components in ink jet technology [2]. We obtained seven different carbon blacks (Vulcan XC72 (Cabot), ISAF (Columbian Carbon), Corax N234g, N115, N220, EB111, Printex XE2 (all from Degussa), and two different carbon nanofibers (PLCNF and SC-CNF (both from Future Carbon)) and used them as solid carriers for Ptnanoparticles. The resulting materials were then tested for electrocatalytic properties. Rather than applying our original protocol for the production of $\mathrm{PtO}_{\mathrm{x}}$ colloids [3a,b], we first developed a simplified version ("instant method') [3c]. $\mathrm{H}_{2} \mathrm{PtCl}_{6}$ or other transition metal salts are hydrolyzed in the $a b$ sence of a colloid stabilizer, but in the presence of a suitable solid support such as Vulcan XC72 which leads to in situ immobilization of 1-2 nm sized $\mathrm{PtO}_{\mathrm{x}}$ particles before undesired precipitation of bulk metal oxide can occur. Very high metal loadings necessary for real applications are possible, easily reaching $60 \%$. We therefore applied the 'instant method' to the genera- tion and immobilization of $\mathrm{PtO}_{\mathrm{x}}$-nanoparticles on various types of carbon carriers, and the materials were then reduced electrochemically to the corresponding $\mathrm{Pt} / \mathrm{C}$ materials.

$\mathrm{H}_{2} \mathrm{PtCl}_{6}+\mathrm{C} \stackrel{\mathrm{Li}_{2} \mathrm{CO}_{3} / \mathrm{H}_{2} \mathrm{O}}{\longrightarrow} \mathrm{PtO}_{x} / \mathrm{C} \stackrel{\text { Reduction }}{\longrightarrow} \mathrm{Pt} / \mathrm{C}$

High-resolution transmission electron microscopy (HRTEM) reveals the presence of 1-2 nm sized $\mathrm{PtO}_{\mathrm{x}}$ particles in all cases, which upon reduction remain dispersed, although in most cases with agglomeration. For the measurements catalyst suspensions were attached with Nafion to glassy carbon electrodes [6] before multiple potential scans between 0.05 and $1.2 \mathrm{~V}$ (NHE) were performed. Fig. 1 shows the results for the commercial ETEK-catalyst and one of our catalysts (Pt/Printex XE2). Peak positions for hydrogen adsorption/desorption are similar. Therefore $\mathrm{PtO}_{\mathrm{x}} / \mathrm{C}$ is reduced to $\mathrm{Pt} / \mathrm{C}$. However, the charge originating from hydrogen adsorption/desorption is different. The electrochemically accessible platinum area was calculated from the charge for hydrogen adsorption $Q_{H}$ and the particle size $d$ was roughly approximated by cyclic voltammetry (CV) according to the method of Geniès [7]. The results of the different particle size measurements, $d$ (TEM) and $d(\mathrm{CV})$, show a good agreement (Table).

In order to determine the electrochemical activity for oxygen reduction, rotating disc electrode measurements were performed. All materials were first reduced electrochemically to Pt/C. Then the current was measured at a potential at which the oxygen reduction occurs in a kinetically 


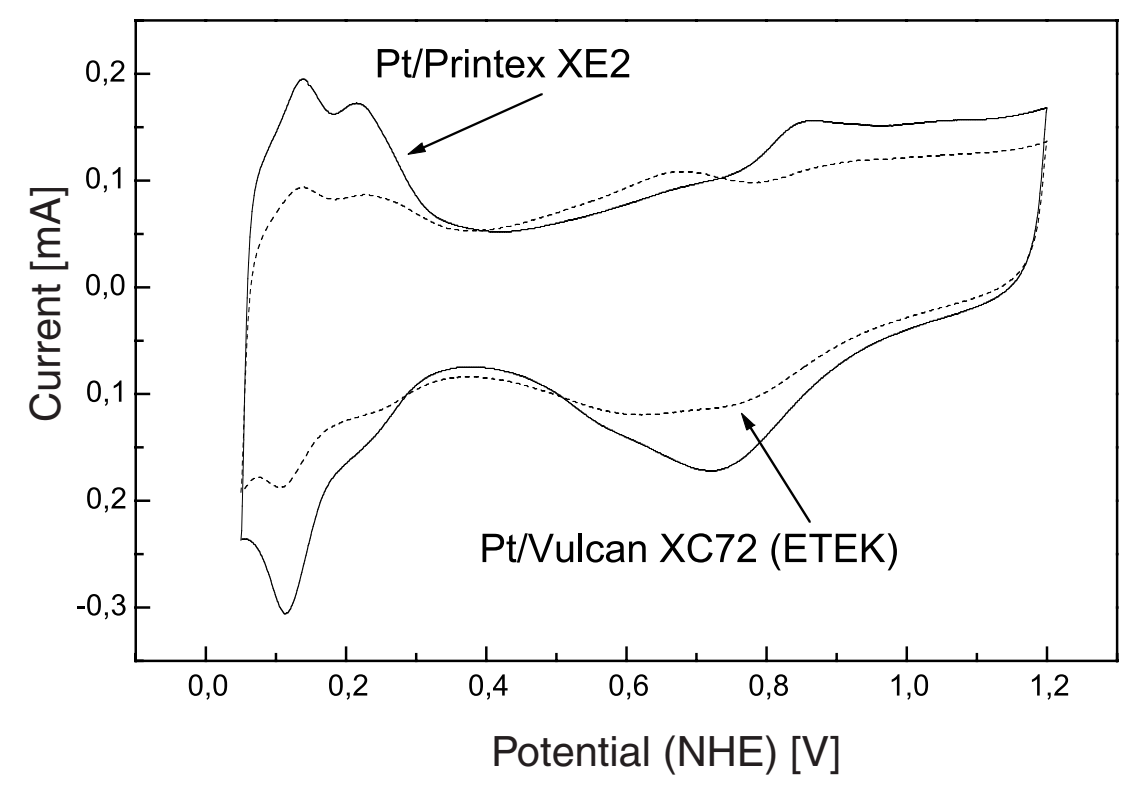

Fig. 1. Solid line: Cyclic voltammogram of Pt/Printex XE2 catalyst (63\% metal loading, $2.128 \mu \mathrm{g} \mathrm{Pt}$ ). Dotted line: Commercial Pt/Vulcan XC72 catalyst from ETEK (58\% metal loading, $2.32 \mu \mathrm{g} \mathrm{Pt}$ ). Scan rate $100 \mathrm{mV} / \mathrm{s}$, electrolyte is Ar-saturated $0.5 \mathrm{M}$ perchloric acid.

Table. Characterization of $\mathrm{Pt} / \mathrm{C}$ catalysts for $\mathrm{O}_{2}$-reduction

\begin{tabular}{|c|c|c|c|c|c|c|c|}
\hline Catalyst & $\begin{array}{l}\text { Metal } \\
\text { Loading } \\
\text { (EDX) } \\
\text { [\% Pt] }\end{array}$ & $\begin{array}{l}Q_{H} \\
{\left[\mathrm{C} / \mathrm{g}_{\mathrm{Pt}}\right]}\end{array}$ & $\begin{array}{l}\text { Mass Activity } \\
\text { at } 0.9 \mathrm{~V} \\
{\left[\mathrm{~A} / \mathrm{g}_{\mathrm{Pt}}\right]}\end{array}$ & $\begin{array}{l}\text { Surface } \\
\text { Activity } \\
\text { at } 0.9 \mathrm{~V} \\
{\left[\mu \mathrm{A} / \mathrm{cm}^{2}\right]}\end{array}$ & $\begin{array}{l}d(\mathrm{TEM}) \\
\text { of } \mathrm{PtO}_{\mathrm{x}} \\
{[\mathrm{nm}]}\end{array}$ & $\begin{array}{l}d(\text { TEM) } \\
\text { of Pt } \\
{[\mathrm{nm}]}\end{array}$ & $\begin{array}{l}d(\mathrm{CV}) \\
\text { of Pt } \\
{[\mathrm{nm}]}\end{array}$ \\
\hline $\begin{array}{l}\text { Pt/Vulcan } \\
\text { (ETEK) }\end{array}$ & 58 & 62 & 38 & 127 & - & $8-10$ & 9.5 \\
\hline $\begin{array}{l}\text { Pt/Vulcan } \\
\text { XC72 }\end{array}$ & 55 & 76 & 35 & 96 & $1.9 \pm 0.5$ & n.d. & 7.7 \\
\hline $\begin{array}{l}\text { Pt/Printex } \\
\text { XE2 }\end{array}$ & 63 & 150 & 51 & 71 & $2.2 \pm 0.6$ & $3.2 \pm 0.9$ & 3.9 \\
\hline
\end{tabular}

controlled process: at $0.9 \mathrm{~V}$ (NHE). It turned out that all but one of the materials produced from the various carbon carriers display similar or smaller specific hydrogen adsorption/desorption peaks compared to the standard $\mathrm{Pt} / \mathrm{C}$ system based on Vulcan XC72. Also, the specific catalytic activity for oxygen reduction is in most cases lower than for the Pt/Vulcan XC72 catalyst. In the case of Printex XE2 (a carbon black used in ink jets), very different results were obtained. The Table compares the properties of this material with those of two other carbon black systems (the standard $\mathrm{Pt} / \mathrm{C}$ produced by our method and commercial Pt/C, both utilizing Vulcan XC72). It can be seen that the electrocatalytic activity of $\mathrm{Pt} / \mathrm{C}$ prepared by the 'instant method' using Vulcan $\mathrm{XC72}$ as the support is very similar to that of the commercial catalyst Pt/C (ETEK). In surprising contrast, the $\mathrm{Pt} / \mathrm{C}$ system derived from Printex XE2 results in a $34 \%$ increase in electrocatalytic activity. Moreover, the area of the hydrogen adsorption peak is much larger in the case of the electrocatalyst derived from Printex XE2 than it is in the commercial Pt/C (ETEK) material (see also $Q_{H}$ values in the Table). Importantly, the electrochemically accessible Pt-surface of our material is about twice as large.

In order to shed light on the reason(s) for these remarkable results, we carried out HRTEM studies of the various carbon black supports before and after platinum loading as well as after electrochemical reduction. Fig. 2 displays the results obtained for the sample derived from Vulcan XC72, and Fig. 3 those from the Printex XE2 sample.
Close inspection of the HRTEM images of the untreated carbon black supports reveals a quite smooth surface in the case of Vulcan XC72, whereas Printex XE2 has a 'rougher' texture (Fig. 2a/2a' versus Fig. $3 \mathrm{a} / 3 \mathrm{a}$ '). Upon immobilization of $\mathrm{PtO}_{\mathrm{x}}$, platinum oxide nanoparticles of 1-2 nm size appear in both cases, but the degree of dispersion is a little higher in the case of the Printex XE2-based pre-catalyst (Fig. 2b/2b'versus Fig. 3b/3b'). Significantly, upon electrochemical reduction to $\mathrm{Pt} / \mathrm{C}$, dramatic differences in the two systems become visible. In the case of Vulcan XC72 a pronounced increase in the average size of the Pt-nanoparticles as well as a great deal of agglomeration occurs (Fig. 2c/2c'). The electrochemically determined Pt-particle size is $7.7 \mathrm{~nm}$ (Table). Thus, two very different methods point to the same results which are in good agreement. We also observed large agglomerated Pt-particles in the case of the industrial ETEK catalyst! In sharp contrast, under operating conditions undesired particle growth and agglomeration in the case of the Printex XE2 carbon support are much less pronounced (3.2 \pm $0.9 \mathrm{~nm}$ by TEM as shown in Fig. 3c/3c' and $3.9 \mathrm{~nm}$ by cyclic voltammetry). This clearly identifies the reason why the Printex XE2 material is the better electrocatalyst. Smaller Pt-nanoparticles are more active than larger and agglomerated analogs with a lower percentage of active surface Pt-sites. Of course, in any practical preparative method partial contamination of $\mathrm{Pt}$ is to be expected, but this phenomenon cannot explain the dramatic difference in electrocatalytic activity. The identical preparation method performed under carefully controlled conditions using two (or more) different carbon supports cannot lead to significantly different degrees of contamination. Moreover, extreme care was undertaken to ensure reproducibility, which is excellent.

At this time we favor the simplest explanation for the above observations, namely that the clear difference in observed Ptparticle size under operating conditions is the cause of the different electrocatalytic properties [8]. Moreover, in the case of the other carbon supports ISAF (Columbian Carbon), Corax N234g, N115, N220 and EB111 (all from Degussa) and the two carbon nanofibers PL-CNF and SC-CNF (both from Future Carbon), extensive Pt-particle growth $(6-9 \mathrm{~nm})$ with agglomeration and low electrocatalytic activity were observed. In all of these cases relatively smooth surfaces as visualized by HRTEM pertain. The correlation between electrocatalytic activity and surface structure became even more evident upon studying further carbon supports. Out of a total of 15 different carbon supports four hits showing enhanced electrocatalytic activity ( $>30 \%$ increase) were 

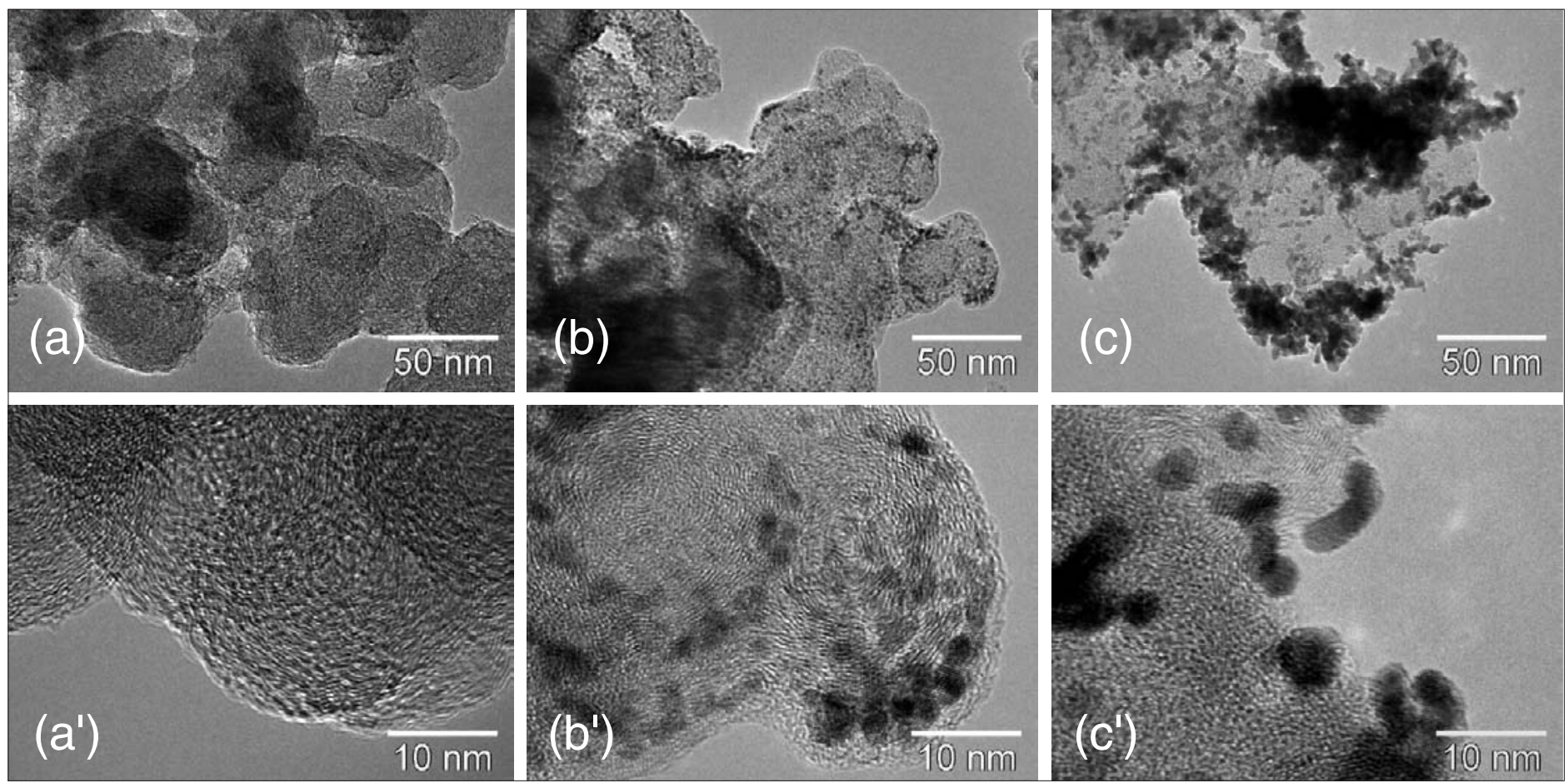

Fig. 2. HRTEM images of Vulcan XC72-based materials: Unloaded carbon support in an overview (a) and high resolution (a'); PtO $_{x}$-loaded carbon support in an overview (b) and high resolution (b'); Pt/C following electrochemical reduction in an overview (c) and high resolution (c').
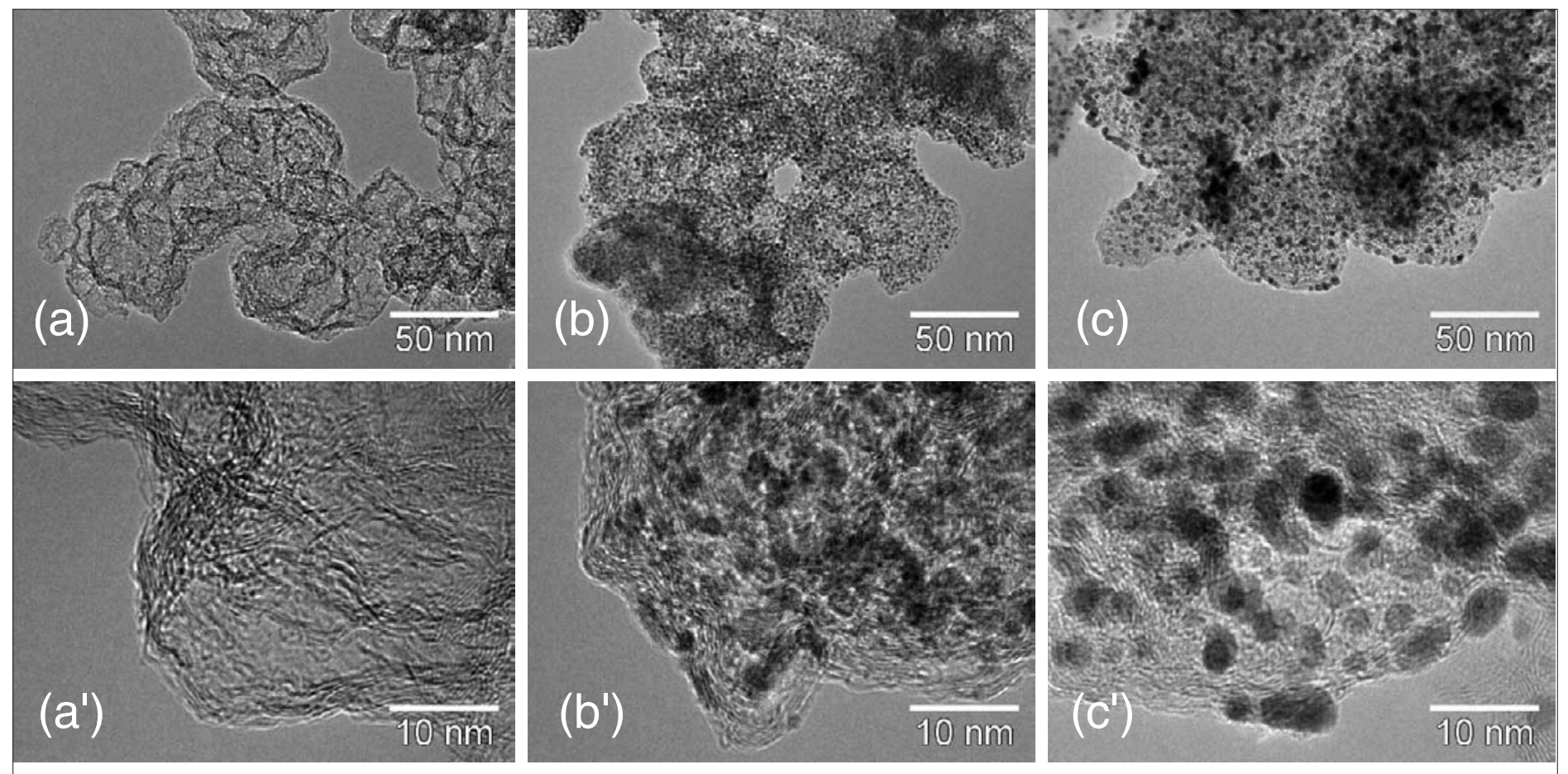

Fig. 3. HRTEM images of Printex XE2-based materials: Unloaded carbon support in an overview (a) and high resolution (a'); $\mathrm{PtO}_{\mathrm{x}}$-loaded carbon support in an overview (b) and high resolution (b'); Pt/C following electrochemical reduction in an overview (c) and high resolution (c').

identified, all showing relatively rough surfaces and limited Pt-particle growth. In contrast, the 11 other supports turned out to have relatively smooth surfaces (in the untreated support) as well as pronounced Ptparticle growth following reduction to Pt/C. But why does extensive undesired agglomeration occur in one system and not in the other?
We believe that it is primarily the roughness of the carbon black surface which inhibits uncontrolled particle growth and agglomeration. This in turn prevents a decrease in electrocatalytic activity. The relatively rough texture also enhances the ease of metal immobilization, especially when aiming for high loading (up to 60\%). We noticed that the process of metal immo- bilization occurs considerably faster with the Printex XE2 support than with carbon blacks having a smoother surface. We have also immobilized $\mathrm{PtRuO}_{\mathrm{x}}, \mathrm{PtCoO}_{\mathrm{x}}$ and Pt$\mathrm{CrO}_{\mathrm{x}}$ colloids [3c] on Printex $\mathrm{XE} 2$, metal loadings of $50-60 \%$ posing no problems when employing this support. The surface areas of the unloaded supports as measured by $\mathrm{N}_{2}$-adsorption according to the BET- 
method also vary $\left(250 \mathrm{~m}^{2} / \mathrm{g}\right.$ for Vulcan XC72 and $1000 \mathrm{~m}^{2} / \mathrm{g}$ for Printex XE2) [2]. Of course, this includes any $\mathrm{N}_{2}$-adsorption in the pores, which means that such numbers need to be interpreted with care.

In summary, our studies show that variation in the type of carbon black used in the immobilization of Pt-nanoparticles has a profound influence on the ease of Pt-loading and on the respective electrocatalytic profile. Enhanced electrocatalytic activity can be expected from carbon black supports such as Printex XE2 or analogs which have a relatively rough surface, because this minimizes undesired Pt-particle growth and agglomeration under operating conditions. An increase in specific electrocatalytic activity for oxygen reduction by $34 \%$ relative to the standard Pt/Vulcan (ETEK) is possible, even though we have not optimized the procedure. The results of our study can be expected to influence future research in fuel cells.

\section{Acknowledgements}

We thank the Fonds der Chemischen Industrie for support and A. Dreier and H. Bongard for help in TEM and EDX measurements.

Received: October 29, 2004
[1] a) L. Carrette, K.A. Friedrich, U. Stimming, ChemPhysChem 2000, 1, 162-193; b) E. Reddington, A. Sapienza, B. Gurau, R. Viswanathan, S. Sarangapani, E.S. Smotkin, T.E. Mallouk, Science 1998, 280, 1735-1737; c) W. Vielstich, A. Lamm, H.A. Gasteiger, 'Handbook of Fuel Cells: Fundamentals Technology and Applications', Vol. 2, John Wiley \& Sons Inc., New York, 2003; d) H. Bönnemann, R.M. Richards, Eur. J. Inorg. Chem. 2001, 2455-2480; e) K.-Y. Chan, J. Ding, J. Ren, S. Cheng, K.Y. Tsang, J. Mater. Chem. 2004, 14, 505-516.

[2] Reviews of carbon black materials: a) R. Schlögl, in 'Handbook of Heterogeneous Catalysis', Eds. G. Ertl, H. Knözinger, J. Weitkamp, VCH, Weinheim, 1997, pp. 138-191; b) H.P. Böhm, Carbon 1994, 32 , 759-769; c) E. Auer, A. Freund, J. Pietsch, T. Tacke, Appl. Catal. A 1998, 173, 259-271.

[3] a) M.T. Reetz, M.G. Koch, J. Am. Chem. Soc. 1999, 121, 7933-7934; b) M.T Reetz, M. Lopez, W. Grünert, W. Vogel, F. Mahlendorf, J. Phys. Chem. B 2003, 107, 7414-7419; c) M.T. Reetz, M. Lopez, Patent Application DE-A 102 11701.2, 16.03.2002.
[4] a) J.M. Thomas, W.J. Thomas, 'Principles and Practice of Heterogeneous Catalysis', $\mathrm{VCH}$, Weinheim, 1997; b) 'Handbook of Heterogeneous Catalysis', Eds. G. Ertl, H. Knözinger, J. Weitkamp, VCH, Weinheim, 1997.

[5] Although much more expensive than carbon blacks, carbon nanotubes and ordered mesoporous carbons have been used in electrocatalysis [1e]. See also: T. Matsumoto, T. Komatsu, K. Arai, T. Yamazaki, M. Kijima, H. Shimizu, Y. Takasawa, J. Nakamura, Chem. Commun. (Cambridge, U.K.) 2004, 840-841.

[6] T.J. Schmidt, H.A. Gasteiger, G.D. Stäb, P.M. Urban, D.M. Kolb, R.J. Behm, J. Electrochem. Soc. 1998, 145, 2354-2358.

[7] L. Geniès, R. Faure, R. Durand, Electrochim. Acta 1998, 44, 1317-1327.

[8] Although we have applied our own method of $\mathrm{PtO}_{\mathrm{x}}$ colloid formation and immobilization, the conclusions drawn in our paper are independent of how Pt or other metals are supported on carbon blacks. Of course, we are aware of the possibility that surface oxidation of the carbon blacks and the degree of graphitization can also play a role. 